In confirmation whereof the Ministers of Foreign Affairs of both countries have, subject to ratification, signed this protocol, which has been prepared in two copies in the Danish and Norwegian languages, in Copenhagen on July 18th 1945."

(Signed) J. Christmas Möller Trygve Iie.

The Treaty of 9 July 1924 provided that: "In East Greenland, by which is understood that part of the east coast of Greenland with its adjacent waters which lies from Lindenov Fjord to Nordostrundingen, with the exception of the district of Angmagssalik", there should be free access for the ships of both parties, for hunting and fishing by the subjects of both parties, and for the occupation of land by those subjects for their own use. The Treaty also laid down that differences between the two parties should be submitted to the Hague Court, and in notes which were exchanged simultaneously with the signature of the Treaty, each party reserved its point of view regarding questions of principle. The rights accorded to Norwegians under this Treaty were subsequently extended to British subjects by an exchange of notes on 4 June 1925 and to French citizens by the exchange of notes on 19 October 1925, in view of the most-favoured-nation clauses of Treaties of Commerce between Denmark and Great Britain and Denmark and France respectively.

\title{
DEVELOPMENT AND WELFARE IN EAST GREENLAND
}

[Review of "The East Greenlanders: Possibilities of Existence, their Production and Consumption", by Ejnar Mikkelsen, in collaboration with P. P. Sveistrup. Meddelelser om Gronland, Bd. 134, No. 2, 1944, pp. 1-244.]

In this report the responsible Danish official, the Inspector for East Greenland, a traveller of wide experience, summarises in great detail the background and the story of the Danish colonising work. in East Greenland. This work was started in 1894 through the initiative of Gustav Holm. "Half a century has elapsed since the Eskimo population of East Greenland... were made to take the immense and dangerous leap from [the] stone age...." Mikkelsen provides the full picture, from "Living Conditions in East Greenland in Pre-Historic Times" to "Health Conditions of the East Greenlanders after the Colonisation"; from migration routes of the past to the state of the teeth of those alive to-day; the hunting, the trading and the travelling; the consumption of imported foods, the vital statistics; the stocks of seals; the isolation and the contacts; the objects of the whole enterprise and speculations about the future.

Apart from being a compendium of information, the chief interest and importance of this report resides in its description of the development and welfare of a backward race reduced to its very simplest. It is a small, controlled experiment in colonisation, using that term in the British Imperial sense of to-day.

What was and is the Danish objective? Following Gustav Holm's wintering at Angmagssalik in 1884-85, it was realised "that the remainder of the East 
Greenland community, the Angmagssaliks, had outlived themselves and were bound to perish, unless an attempt was made from without to change the trend of development and to create a new foundation for the continued existence of the tribe". In a memorandum of 10 November 1886, the Administration of West Greenland stated their ideal: "[The] land... will be exposed to visits of whalers and fishermen who will try to barter bearskins and foxskins for spirits and the like....Against this danger the population is entitled to the protection of the Danish Government." From the beginning, the selected aims and methods were: "The Angmagssaliks should be christianised." Trading, whether profitable or otherwise, must be established for the sake of the population. Blubber must not become an article of trade. Trade should be limited in the one direction, to firearms, ironware, tobacco and a little clothing (but not food) and, in the other, to sealskins shown to be surplus to the real needs of the community. "Denmark ought to protect the East Greenlanders against uncontrolled trading intercourse and its consequences." These basic principles have been carried into effect, though more food has been imported than had been originally intended. Throughout idealism has been dominant. The Danish administrators in East Greenland have had the encouraging precedent of their West Greenland colonisation both as an example and as an administrative training ground.

Here, in tiny miniature, are the Colonial problems of those who, having idealism, are called upon to administer backward peoples. But here in large degree the problems are at their simplest. There is no large population rapidly increasing, disease and undernourishment are not rife, there is no growth of political fever, and there is no problem created by ignorant criticism by the masses in the home country and elsewhere. In East Greenland there is, however, a similar proportionate increase of population. Moreover, from a tiny figure (about 250 in 1895) to one a little less tiny (about 1050 in 1938), there is the same tendency towards "urbanisation" and with it a change in diet and culture leading to dental caries and tuberculosis. Similarly, there has been the same detrimental effect on the productive power of the environment and the modification of habit decried by the traditionalist.

Nevertheless, by its isolation and freedom from the buffets of world trade, opinion and personal contacts, East Greenland is not far from being a truly controlled experiment in idealistic development. Elsewhere in the world colonisation represents the attempt to steer a primitive people towards tolerant self-government through a storm of obstacles. Yet even in East Greenland difficulties are now arising and are being faced. There is physical deterioration with the increased dependence on imported European carbohydrate foods, necessitated by shortages resulting from hunting over too confined an area. There is the acquired taste for textile clothes which require less effort in manufacture, but are less efficient and protective in use. It is very difficult now to check these tendencies. Something could be done by the manipulation of prices, but that would run the risk of lessened confidence. Much, too, can be done by further education and the provision of savings bank facilities. This path is being followed.

Mikkelsen sees the real solution of the problems in the spreading out of the 
existing population so that the seals, on which the whole culture depends, may be used rationally and over a wider area. This process was started with the deliberate formation of the Scoresby Sund settlement in 1924. There are plenty of further opportunities for dispersion, and planning is needed in order to provide new centres with store and catechist. The second main conclusion is that there is need for international agreement to maintain the area in isolation. Where formerly geography and sea ice were ample, now new barriers must be maintained against harmful personal contacts with tourists, hunters and possible traders. Parallel with this is the need for international rational conservation of the stocks of seals in the North Atlantic. The present progressive decreases of stock have both direct and indirect detrimental effects on the East Greenland culture. It is pointed out that such conservation will be to the eventual advantage of Europeans no less than of the East Greenlanders.

It is stated in conclusion that faults have been recognised, but "nevertheless we are persuaded that this work has been characterised by an unselfish desire to protect and help a small and primitive people, which without this assistance would undoubtedly have perished". The Danes have nobly carried out a worthy and congenial task, and it remains the view of the Greenland Administration that isolation and protection should continue.

G. C. L. BERTRAMI

\section{THE LAPPS OF WEST BOTHNIA, SWEDEN}

[Review of paper " On the History and Conditions of Life of the West Bothnian nomad Lapps, their Food and Health Conditions", by S. Ekvall. Acta Medica Scandinavica, Vol. 105, Fasc. 4, 1940, pp. 329-59.]

This useful paper is based on a lecture given in 1938 at the annual meeting of the Swedish Association of Medicine by S. Ekvall, the Medical Superintendent of the Central Hospital at Umeå, Sweden. It is the story of the gradual transition of the Lapps from the nomadic to the settled life. This transition in our days represents the speeding up of a long-term trend.

The Lapps now number around 30,000. In 1920 it was estimated that there were about 20,000 in Norway, 7000 in Sweden and about 1500 in Russia and the same in Finland. The most recent count (1937) gives a total of 6481 Lapps in Sweden, of whom 2824 kept reindeer, "only $1135(17.5 \%)$ however, subsisting entirely on reindeer-raising". The number of Lapps at that date in the province of West Bothnia, the author's particular concern, was 1923, of whom 353 kept reindeer.

The settling of the nomad Lapps, and the recent speeding up of the process, is typical of the present condition throughout the world of nomad races who are dependent mainly on a single species of domestic animal. The camel-raising Bedu of the Middle East afford an almost exact parallel. For long there have been settled and semi-settled Lapps, and likewise Bedu, retaining more or less of their original culture but living in permanent habitations among the fringes of their neighbours. The present causes accelerating the process of Lapp 